\title{
A través de la ESECH, la UNAM apoya a las comunidades mexicanas residentes en Chicago
}

\author{
Lic. Fausto Vallado Miguel ${ }^{*}$
}

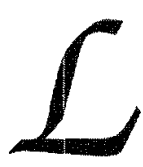

a inmigración de mexicanos hacia Estados Unidos no es un fenómeno reciente, ha existido desde el siglo XIX, ya sea por razones políticas, económicas o sociales. Sin embargo, como resultado de las múltiples crisis económicas que ha sufrido nuestro país en las últimas décadas, se han incrementado el desempleo $y$ la falta de oportunidades en el agro mexicano $y$ ha crecido de manera alarmante el número de connacionales que cruzan la frontera en busca de mejores oportunidades de vida.

Sólo como ejemplo, bástenos saber que actualmente el estado de Jalisco cuenta con una población de 7 millones de habitantes y que en nuestro vecino del norte viven alrededor de 3 millones de jaliscienses, esto es, que la cifra corresponde a casi la mitad de los habitantes de este estado mexicano. También sabemos que en Estados Unidos la población de origen mexicano oscila alrededor de los 20.6 millones, En la ciudad de Chicago, por ejemplo, el número de compatriotas alcanza la suma de 1 millón 500 mil, aproximadamente.

Este fenómeno es una preocupación constante para los gobiernos tanto de México como de la Unión Americana, por lo que es un tema de vital importancia en la agenda de la relación bilateral entre ambas naciones. El 9 de julio de 2001, durante la visita del presidente Vicente Fox Quesada a Chicago, en el estado de Illinois, la Secretaría de Relaciones Exteriores, la Secretaría de Educación Pública, ambas dependencias del gobierno mexicano, y la Universidad Nacional Autónoma de México,

\footnotetext{
* Director de la Escuela de Extensión de Chicago.
}

firmaron un Memorándum de Entendimiento sobre Cooperación Educativa. En el artículo 5 de dicho Memorándum se acordó que la Universidad Nacional Autónoma de México estableciera una oficina en la ciudad de Chicago, cuya misión central, entre otras tareas, fuera la fundación de una Escuela dedicada a la enseñanza y certificación del dominio del idioma español; el desarrollo de programas de difusión cultural y extensión universitaria, así como el intercambio académico en sus diversas modalidades. Asimismo, también se hizo hincapié en que se ofrecería a los inmigrantes mexicanos de dicha ciudad, la oportunidad de terminar sus estudios medios superiores $y$ superiores a través de programas de universidad abierta y a distancia. Además, la UNAM tiene firmado un convenio con la Secretaría de Relaciones Exteriores para apoyar, mediante diversas acciones universitarias, a las comunidades mexicanas en el extranjero.

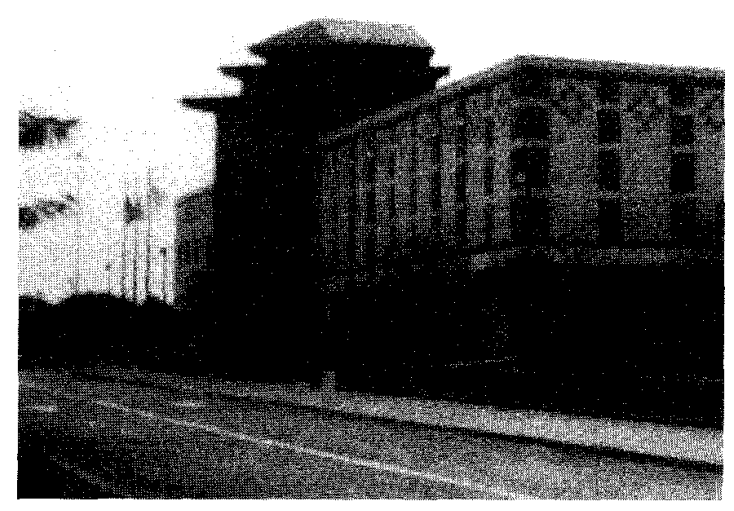

West Side Technical Institute en Chicago, Illionois, E.U.A. 
Para atender este compromiso, el rector Dr. Juan Ramón de la Fuente, en el marco de los 450 años de la fundación de la Universidad, encomendó a la Secretaría General la apertura de una Oficina de Extensión - con el propósito de que a futuro se convierta en Escuela-, a través del Centro de Enseñanza para Extranjeros (CEPE), considerando su amplia experiencia, avalada por 80 años de enseñanza del idioma español y cultura mexicana a extranjeros y el alto nivel de especialización de su profesorado, retomando el modelo de la Escuela de Extensión que tiene la Universidad en San Antonio, Texas, desde 1944, y en Hull, Canadá, desde 1995.

A lo largo de agosto, septiembre y octubre de 2001, después de realizar diversas reuniones de trabajo con autoridades políticas y educativas de Chicago, con los colegios comunitarios y universidades del área de Chicago, así como con el Chicago Public Schools (CPS) y con líderes comunitarios de origen mexicano, se hizo un estudio diagnóstico para detectar las necesidades $y$ determinar la factibilidad $y$ viabilidad del proyecto. Además, con el CPS, en el verano de 2001, se realizó un curso piloto para los maestros del Distrito Escolar 299, que constó de un curso intensivo de dos semanas

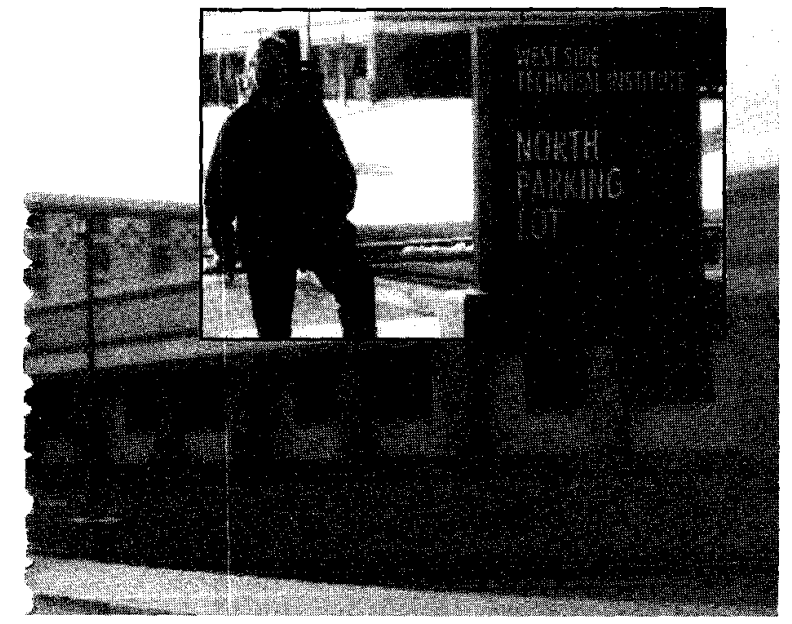

Lic. Fausto Vallado Miguel, en la sede de la ESECH de español, a cargo de personal de la EPESA, impartido en la ciudad de Chicago, y de un paseo por la cultura mexicana, con conferencias de historia, literatura $y$ arte mexicano $y$ visitas a museos, zonas arqueológicas y sitios de interés cultural, así como de una visita a Taxco, Guerrero, a cargo del CEPE-Taxco.

De esta manera, el 19 de octubre de 2001, el Secretario General de la UNAM, licenciado Enrique del Val Blanco - acompañado del Dr. Guillermo Pulido González, director General del CEPE y por el doctor Mario Melgar Adalid, director de la EPESA-, inauguró la Oficina de Extensión de la UNAM en la ciudad de Chicago y encomendó a quien esto escribe la Dirección de dicha Oficina, con la responsabilidad de coordinar los programas académicos, educativos, culturales, sociales, de promoción y de enlace, dirigidos fundamentalmente a los inmigrantes mexicanos, a fin de proyectar la imagen de México y de la propia Universidad en el noreste de Estados Unidos.

Este importante proyecto universitario, incluso antes de su inicio, ha recibido el apoyo incondicional de la Secretaría de Relaciones Exteriores, a través del Cónsul General de México en la ciudad de Chicago, el ingeniero Carlos Manuel Sada Solana, así como de diversas instituciones políticas, educativas y sociales de dicha ciudad. La comunidad mexicana residente en Chicago ha recibido $y$ aplaudido el proyecto $y$ los ex alumnos de la UNAM en esa ciudad han mostrado gran interés por acercarse y apoyar a su Alma Máter.

La alcaldía de la ciudad asignó para las instalaciones de la Escuela de Extensión de Chicago (ESECH) un espacio ubicado en el West Side Technical Institute, que es una escuela de enseñanza técnica para hispanos, situada cerca del barrio mexicano.

La Escuela de Extensión de Chicago, como todas las otras sedes del CEPE en el extranjero, será la embajada educativa y cultural de nuestra 
Universidad en esa ciudad, ya que promoverá el idioma español y la cultura mexicana; apoyará a la UNAM en los programas de actualización y superación académica de sus maestros y alumnos; tendrá programas especiales de apoyo para mexicanos residentes en Chicago, y será un puente de unión entre instituciones de educación superior del noreste de Estados Unidos con la UNAM.

En este sentido, se han entablado pláticas con diversas universidades $y$ centros educativos de Chicago en torno al intercambio en programas de educación, a la certificación del dominio del español, a cursos de español para profesores bilingües, a cursos de inglés como segunda lengua para profesores hispanos e intercambios académicos en diferentes áreas. Es importante destacar que el Columbia College mostró gran entusiasmo e interés por el Diplomado en Estudios Mexicanos que se imparte en español desde el CEPE, en forma presencial $y$ a distancia.

También, la Aurora University manifestó su interés para que la ESECH imparta en el verano de 2002 un curso de español a maestros de Illinois en el campus de esa Universidad, coordinado a través de su College of Education.

Está en estudio la posibilidad de que la Escuela de Extensión en Chicago sea el enlace entre el Illinois Institute of Technology, a través del Chicago-Kent College of Law, $y$ la Facultad de Derecho de la UNAM para la realización de un proyecto de intercambio de profesores $y$ alumnos.

Asimismo, se ha platicado con diversos despachos de abogados que están interesados en participar en diversos cursos de actualización sobre el sistema legal mexicano, reformas en materia fiscal, laboral, mercantil, derechos de autor y derecho bursátil que podrían impartir especialistas de la UMAN a distancia.

Con el City May of Chicago, se estudia la posi- bilidad de ofrecer el examen de proficiencia en español para los empleados del ayuntamiento, en especial para las enfermeras de los hospitales públicos.

Un interés muy específico de nuestros connacionales es poder cursar o concluir sus estudios de educación media superior, por lo que se ofrecerá, en forma adicional, en las instalaciones de la ESECH, un programa piloto de bachillerato bajo el sistema abierto y la metodología de El Colegio de Bachilleres.

A partir del verano próximo, se ofrecerán cursos especiales de cultura mexicana: arte, literatura e historia $y$ los diplomados en Estudios Mexicanos y en Enseñanza de Español a Hispanohablantes para diversos colegios comunitarios y universidades del área de Chicago a distancia, $y$ en el verano 2002, se impartió un curso especial de español $y$ cultura mexicana para el Chicago Public Schools, dirigido a maestros de español de diferentes distritos escolares del área de Chicago y una visita a México en la que participarán el CEPE-CU y el CEPE-Taxco.

Es importante señalar que la UNAM -como entidad certificadora del dominio del españolpodrá aplicar el Examen de Posesión de la Lengua Española (EPLE), a través de la Escuela de Extensión de Chicago en el noreste de Estados Unidos.

En el rubro de la difusión de la cultura mexicana, además de impartir los cursos de arte, historia $y$ literatura, la ESECH tiene una doble tarea: por un lado, la difusión, que se enfocará a que los mexicanos que residen en el área de Chicago recuperen el significado de sus valores y tradiciones culturales, así como el orgullo de su origen, $y$ por otro, promover la cultura mexicana entre los ciudadanos estadounidenses con el propósito de que conozcan $y$ valoren a nuestro país $y$ a nuestros connacionales con quienes comparten ciudad, trabajo $y$ vida 